\title{
Evaluación de la inoculación con microorganismos fijadores de nitrógeno asimbióticos aislados de la rizósfera de Pinus patula en Colombia
}

\author{
Evaluation of inoculation with asymbiotic nitrogen-fixing microorganisms isolated from \\ rhizosphere of Pinus patula in Colombia
}

\author{
Cielo Orozco-Jaramilloa, Patricia Martínez-Nietoa*
}

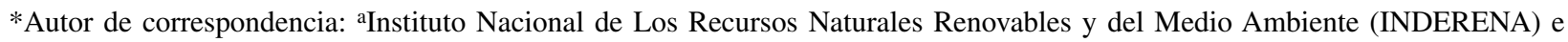
Instituto de Investigaciones Biológicas Alexander von Humboldt, Estación Forestal La Florida, Cota (Cundinamarca, Colombia), patingli@yahoo.com
\end{abstract}

\section{SUMMARY}

The effects on different vegetal parameters of asymbiotic nitrogen-fixing bacteria isolated from the rhizosphere of Pinus patula were studied under greenhouse conditions, in experiments designed for statistical analysis using these forest specie seedlings. This research also examined the interactions of ectomycorrhizal fungus Suillus luteus and the microorganism isolates in $P$. patula, as well as the nitrogenase activity in these bacteria by acetylene reduction assay. The free nitrogen-fixing bacteria Azotobacter chroococcum, Bacillus macerans, Enterobacter agglomerans and Pseudomonas sp., were isolated of the rhizosphere of $P$. patula. Their maximum acetylene-reducing values were 120,18.7, 100, $120 \mathrm{nmol}$ ethylene/tube respectively. Results showed that the best plant growth and nitrogen uptake in the in vivo test in P. patula with these microorganisms and $S$. luteus were observed with A. chroococcum. According to the longitudinal root cuts in the treatments using S. luteus with A. chroococcum, B. macerans, E. agglomerans, or Pseudomonas sp., the fungus with the agglutinated bacteria was showed around the mycorrhizal root surface only in the $S$. luteus and $B$. macerans treatment, but the mycorrhizal infection percentage was low. The inoculation with nitrogen fixing bacteria stimulated longitudinal growth and nitrogenous nutrition of $P$. patula.

Key words: asymbiotic, ectomycorrhizas, nitrogen-fixation.

RESUMEN

El efecto de bacterias fijadoras de nitrógeno asimbióticas aisladas de la rizósfera de Pinus patula sobre diferentes parámetros vegetales fue estudiado bajo condiciones de invernadero, usando plántulas de esta especie forestal. Esta investigación también examinó la interacción entre el hongo ectomicorrízico Suillus luteus y los microorganismos aislados en P. patula, así como la actividad de la nitrogenasa por el ensayo de reducción de acetileno. De la rizósfera de $P$. patula se aislaron las bacterias fijadoras libres de nitrógeno Azotobacter chroococcum, Bacillus macerans, Enterobacter agglomerans y Pseudomonas sp. Los valores máximos de reducción de acetileno presentados por estas bacterias fueron 120,18, 7, 100, $120 \mathrm{nmol}$ etileno/tubo, respectivamente. Los resultados en el ensayo in vivo de $P$. patula con estos microorganismos y S. luteus mostraron que el mejor crecimiento de las plantas y la captación de nitrógeno se observaron con A. chroococcum. Al observar los cortes longitudinales de raíz de los tratamientos usando $S$. luteus con las diferentes bacterias (A. chroococcum, B. macerans, E. agglomerans y Pseudomonas sp.) sólo el tratamiento con $S$. luteus y B. macerans presentó el hongo con bacterias aglutinadas alrededor de la superficie de la raíz micorrizada, pero el porcentaje de micorrización fue bajo. La inoculación con bacterias fijadoras de nitrógeno estimuló el crecimiento longitudinal y la nutrición nitrogenada de $P$. patula.

Palabras clave: asimbiótico, ectomicorrizas, fijación de nitrógeno.

\section{INTRODUCCIÓN}

El proceso de fijación de nitrógeno es importante en los ecosistemas forestales, fijando al año entre $0,5-5 \mathrm{~kg}$ $\mathrm{ha}^{-1}$ (Fisher y Binkley 2000). Los microorganismos que llevan a cabo este proceso representan aproximadamente el 5\% de la población bacteriana total y se encuentran en la superficie de varios órganos de los árboles, tejidos radiculares y foliares, suelo y tubérculos de ectomicorri- zas (Chanway 1999, Rösch et al. 2002, Paul et al. 2007). Además, estas bacterias al ser usadas en la regeneración artificial de bosques, incrementan el desarrollo de plántulas de diferentes especies de coníferas (Chanway 1997).

En Colombia existen cerca de 150.000 hectáreas de bosques productivos, plantados principalmente en la región andina y amazónica, donde un $70 \%$ son especies forestales introducidas como teca (Tectona grandis L. F), araucaria (Araucaria araucana (Mol.) K. Koch.), urapán (Fraxinus 
chinensis Roxb.), ciprés (Cupressus lusitanica Mill.) y diversos pinos (Pinus spp. L.) (Varón 1999, Presidencia de la República de Colombia 2005). Estas plantaciones comerciales se ubican generalmente en tierras agrícolas abandonadas y de fertilidad baja (DAMA y Corporación Suna Hisca 2003), generando varios inconvenientes desde las fases iniciales de crecimiento, entre los que se encuentran problemas en fertilización nitrogenada y fosfatada, bajo porcentaje de micorrización y desarrollo de enfermedades (León et al. 1993).

Los bosques de Pinus patula Schlecht et Cham se localizan en altitudes por encima de $1.800 \mathrm{~m} \mathrm{snm}$, principalmente sobre suelos de cenizas volcánicas que se caracterizan por ser deficientes en nitrógeno y fósforo, además de mostrar una población bacterial menor en comparación con suelos con coberturas agrícolas (Villegas 2004). Industrialmente su madera es muy apreciada y se utiliza en algunas construcciones campestres, postes para el servicio público en zonas rurales, durmientes, pilotes, vigas, columnas, pulpa para papel, madera aserrada, cajas y empaques (León et al. 1993, González-Rubio 2004).

Publicaciones colombianas referentes a bacterias nativas fijadoras asimbióticas de nitrógeno diferentes a Azospirillum y Azotobacter en especies forestales son limitadas, lo mismo que estudios sobre interacciones tripartitas entre hongos ectomicorrízicos, bacterias fijadoras de nitrógeno y forestales. Se han aislado las bacterias diazotróficas Pseudomonas sp., Bacillus sp., Klebsiella pneumoniae y Enterobacter gergoviae de las especies forestales nativas cedro rosado (Cedrela montana Turczaninov), pino romeron (Nageia rospigliosii Pilger Laubenfels), encenillo (Weinmannia tomentosa L.f) y pagoda (Escallonia myrtilloides L.f) (Deaza y Mesa 1996, Jiménez 1996, Parra 1996, Martínez-Nieto y García-González 2002). La demostración de interacciones entre microorganismos fijadores de nitrógeno con micorrizas es un aporte importante para la industria forestal, debido a que las plantaciones de coníferas se realizan en su mayoría en suelos de baja fertilidad. Por esta razón, el propósito de este estudio es determinar el efecto de microorganismos fijadores asimbióticos de nitrógeno aislados de $P$. patula sobre diferentes parámetros vegetales en esta especie forestal. Además determinar en $P$. patula el efecto de coinoculación del hongo ectomicorrízico $S$. luteus y bacterias diazotróficas.

\section{MÉTODOS}

Selección de sitios y toma de muestras. Se seleccionaron cinco zonas de plantaciones representativas de $P$. patula localizadas en el municipio de Cota (Cundinamarca, Colombia).

Las muestras se tomaron por triplicado de la rizósfera de 15 árboles por plantación forestal, siguiendo las normas recomendadas por Novo (1993).
Cultivo, aislamiento e identificación. Se sembró un gramo de suelo en caldos libres de nitrógeno (malato o glucosa como fuente de carbono) y en medios enriquecidos para Azotobacter sp. (caldo Asbhy, Lipman y Jensen). Los cultivos se incubaron en atmósfera aeróbica a $30^{\circ} \mathrm{C}$ (Novo 1993). Después de detectado crecimiento se inocularon en los respectivos medios sólidos durante 48 horas. De acuerdo con la morfología colonial y microscópica se repicaron en agar nutritivo, agar Mac Conkey, agar semisólido malato libre de nitrógeno (NFs) y Asbhy. Una vez purificados se procedió a la caracterización de estos aislamientos mediante pruebas bioquímicas específicas (Holt et al. 1994).

Ensayo in vivo de fijadores de nitrógeno. Este ensayo se distribuyó en un diseño completo al azar, con once tratamientos, tres repeticiones y cinco unidades experimentales por repetición (cuadro 1). Las variables evaluadas fueron: altura, número de hojas, biomasa aérea, biomasa radicular, contenido de nitrógeno del suelo y foliar. Las raíces de plántulas entre 4-6 cm de $P$. patula fueron sumergidas en $5 \mathrm{~mL}$ de la suspensión bacteriana o micelial de acuerdo al experimento y transferidas a 175 bolsas plásticas que contenían suelo estéril-arena (1:1). Posteriormente se procedió a inocular la tierra con $10 \mathrm{~mL}$ de la suspensión bacteriana según tratamiento (Fujii et al. 1987, Orozco 1989). El experimento se mantuvo bajo condiciones de invernadero por un año con una temperatura promedio de $24^{\circ} \mathrm{C}$, humedad de rocío y buena penetración de luz. Se utilizó un suelo de textura franca, $\mathrm{pH}$ ácido $(5,6)$ y un contenido de materia orgánica de 7,5\%.

Cuadro 1. Tratamientos utilizados en el diseño experimental completo al azar.

Treatments used in the fully randomized experimental design.

\begin{tabular}{cl}
\hline Tratamiento & \multicolumn{1}{c}{ Descripción } \\
\hline 1 & Pseudomonas sp. \\
2 & Bacillus macerans \\
3 & Enterobacter agglomerans \\
4 & Suillus luteus \\
5 & S. luteus + Pseudomonas sp. \\
6 & S. luteus + B. macerans \\
7 & S. luteus + E. agglomerans \\
8 & S. luteus + Pseudomonas sp., B. macerans, \\
& E. agglomerans y Azotobacter chroococcum \\
9 & A. chroococcum \\
10 & Suelo no inoculado \\
\hline
\end{tabular}

El inóculo del hongo $S$. luteus se preparó de acuerdo con la metodología descrita por Orozco (1989) y los microbianos se obtuvieron a partir de cultivos puros de las cinco bacterias diazotróficas aisladas, a una concentración equivalente a $5 \times 10^{8} \mathrm{UFC} / \mathrm{mL}$ (Fujii et al. 1987). 
Porcentaje de micorrización. La preparación y lectura de los cortes longitudinales de las raíces de los tratamientos donde se inoculó el hongo S. luteus se hizo siguiendo la metodología de Alvarado (1989) y Orozco (1989). Los segmentos de raíces de $0,5 \mathrm{~cm}$ de longitud fueron coloreados con azul de tripano en lactofenol y se observaron al microscopio en $40 \mathrm{X}$, dividiendo la lectura en cuatro campos equivalentes al $100 \%$.

Análisis estadístico. Todos los experimentos fueron evaluados por análisis de varianza de una sola vía. La diferencia entre tratamientos se hizo mediante la prueba de rango múltiple de Duncan $(P<0,01)$.

Actividad de la nitrogenasa. La actividad del complejo enzimático nitrogenasa se midió cada tres horas a presión atmosférica, por el ensayo de reducción de acetileno (ARA) en medio NFs, durante 30 horas. La producción de etileno se midió por cromatografía de gases con detector de ionización de llama (FID) y con nitrógeno como gas de arrastre, de acuerdo con la metodología estandarizada en el laboratorio de Recursos Biofísicos de la Corporación Colombiana de Investigación Agropecuaria, CORPOICA. La actividad de reducción de acetileno se registró contra el número de fijadores de nitrógeno calculado en $\mathrm{UFC} / \mathrm{mL}$.

\section{RESULTADOS}

Cultivo, aislamiento e identificación. De un total de 151 cepas de bacterias aerobias aisladas de la rizósfera de $P$. patula, se recuperaron 62 cepas fijadoras de nitrógeno. Las pruebas bioquímicas sugieren que las bacterias diazotróficas son cercanas a las especies $B$. macerans (35,5\%), Pseudomonas sp. (29\%), E. agglomerans $(22,6 \%)$ y A. chroococcum $(12,9 \%)$.

Ensayo in vivo de fijadores de nitrógeno. Las plántulas inoculadas con A. chroococcum presentaron los mejores promedios en casi todos los parámetros vegetales, a excepción del peso seco radicular, y de acuerdo con la prueba de rango múltiple de Duncan no hubo diferencias significativas con algunos tratamientos microbianos $(P>0,01)$ (cuadro 2). Además, los resultados muestran incrementos en la captación de nitrógeno y baja pérdida de este elemento en el suelo en las plántulas inoculadas con bacterias en comparación con las no inoculadas.

Porcentaje de micorrización. La mayor micorrización se obtuvo con los tratamientos S. luteus (30\%) y S. luteus con Azotobacter (26,7\%), no encontrando diferencias significativas entre ellos, según la prueba de rango múltiple de Duncan (cuadro 2). En el caso de B. macerans con el hongo ectomicorrízico se observó un porcentaje de micorrización de $8,3 \%$ y en los demás tratamientos con $S$. luteus no se encontró colonización micorrizal.

Los grados de infección en los tratamientos donde se encontró colonización por el hongo se pueden considerar moderados (entre 20-50\%) para S. luteus y S. luteus con Azotobacter y bajos para B. macerans y $S$. luteus (entre $1-20 \%$ ).

En los cortes longitudinales de las raíces del tratamiento con S. luteus y A. chroococcum sólo se observó el hongo ectomicorrízico. La observación microscópica de cortes longitudinales de raíz del tratamiento con Pseudomonas sp. y S. luteus mostró bacilos aglutinados

Cuadro 2. Evaluación de la inoculación con bacterias fijadoras de nitrógeno sobre diferentes parámetros vegetales en $P$. patula.

Evaluation of inoculation with nitrogen-fixing bacteria on different plant parameters in P. patula.

\begin{tabular}{|c|c|c|c|c|c|c|}
\hline \multirow[b]{2}{*}{ Tratamientos } & \multicolumn{6}{|c|}{ Parámetros vegetales } \\
\hline & $\begin{array}{c}\text { Altura } \\
\text { plantas** } \\
\mathrm{cm}\end{array}$ & $\begin{array}{c}\text { Peso } \\
\text { seco } \\
\text { foliar** } \\
\mathrm{g}\end{array}$ & $\begin{array}{c}\text { Peso } \\
\text { seco } \\
\text { radicular** } \\
\mathrm{g}\end{array}$ & $\begin{array}{l}\text { Contenido de } \\
\text { nitrógeno } \\
\text { foliar** } \\
\text { g/planta }\end{array}$ & $\begin{array}{l}\text { Contenido de } \\
\text { nitrógeno en } \\
\text { suelo** } \\
\mathrm{g} / \mathrm{cm}^{3}\end{array}$ & $\begin{array}{c}\text { Porcentaje } \\
\text { de } \\
\text { micorrización** } \\
\%\end{array}$ \\
\hline Pseudomonas sp. & $15,1 \mathrm{abc}$ & $22,9 \mathrm{~d}$ & $6,7 d$ & $0,38 b$ & $1,56 \mathrm{ab}$ & - \\
\hline B. macerans & $18,6 \mathrm{a}$ & $26,2 \mathrm{c}$ & $18,6 b$ & $0,40 \mathrm{~b}$ & $1,22 \mathrm{e}$ & - \\
\hline E. agglomerans & $17,2 \mathrm{ab}$ & $30,9 b$ & $22,9 a$ & $0,43 b$ & $1,33 \mathrm{de}$ & - \\
\hline S. luteus & $15,3 \mathrm{abc}$ & $29,5 b$ & $11,6 \mathrm{~d}$ & $0,37 b$ & $1,43 \mathrm{bcd}$ & $30 \mathrm{a}$ \\
\hline S. luteus + Pseudomonas sp. & $15,6 \mathrm{abc}$ & $26,1 \mathrm{c}$ & $6,9 \mathrm{~d}$ & $0,43 b$ & $1,48 b c$ & $0 \mathrm{c}$ \\
\hline S. luteus + B. macerans & $7,3 \mathrm{e}$ & $4,6 \mathrm{~g}$ & $4,3 \mathrm{e}$ & $0,07 \mathrm{~d}$ & $1,37 \mathrm{~cd}$ & $8,3 b$ \\
\hline S. luteus + E. agglomerans & $8,9 \mathrm{de}$ & $5,6 \mathrm{~g}$ & $4,4 \mathrm{e}$ & $0,08 \mathrm{~d}$ & $1,09 f$ & $0 \mathrm{c}$ \\
\hline S. luteus + Mezcla bacterias & $12,1 \mathrm{~cd}$ & $9,1 \mathrm{f}$ & 4,96 & $0,16 \mathrm{~d}$ & $1,46 \mathrm{bcd}$ & $0 \mathrm{c}$ \\
\hline A. chroococcum & $18,7 \mathrm{a}$ & $37,4 \mathrm{a}$ & $16,6 \mathrm{c}$ & $0,72 \mathrm{a}$ & $1,64 \mathrm{a}$ & - \\
\hline Suelo no inoculado & $10,0 \mathrm{de}$ & $10,5 \mathrm{f}$ & $6,4 \mathrm{~d}$ & $0,13 \mathrm{~d}$ & $0,98 \mathrm{f}$ & - \\
\hline A. chroococcum + S. luteus & $14,5 \mathrm{bc}$ & $17,6 \mathrm{e}$ & $22,3 \mathrm{a}$ & $0,23 \mathrm{c}$ & $1,07 f$ & $26,7 \mathrm{a}$ \\
\hline
\end{tabular}

** $\quad P<0,01$. Los datos representan los promedios de las tres réplicas. Las letras indican los niveles de la prueba de rango múltiple de Duncan, donde letras iguales indican promedios estadísticamente iguales. El primer nivel está representado por la letra a. 
alrededor de la raíz pero no se encontró la presencia del hongo S. luteus. Lo mismo ocurrió con E. agglomerans, pero en este caso no se presentó aglutinación bacteriana; mientras que en el tratamiento con $B$. macerans y el hongo, los dos estuvieron presentes y la bacteria aglutinada alrededor de la raíz.

Ensayo de la nitrogenasa. En el ensayo realizado cada tres horas se pudieron ver comportamientos diferentes en las bacterias fijadoras de nitrógeno. Bacillus macerans, E. agglomerans y A. chroococcum presentaron la mayor actividad a las tres horas de incubación con acetileno,
Pseudomonas sp. a las 24 horas y la mezcla a las 15 horas. Bacillus macerans presentó dos picos de gran actividad a las 3 y 18 horas. La actividad de la enzima varió entre 0-18,7 nmol etileno/tubo para Pseudomonas sp., de 0-120 nmol/tubo en B. macerans, 0-110 nmol/tubo en E. agglomerans, de 0-120 nmol/tubo en $A$. chroococcum y en la mezcla de 0-99,8 nmol etileno/tubo (figura 1).

El comportamiento de la biomasa microbiana durante la incubación con acetileno no presentó un crecimiento apreciable a excepción de $A$. chroococcum y la mezcla de bacterias donde hay una más o menos definida fase logarítmica (figura 2).

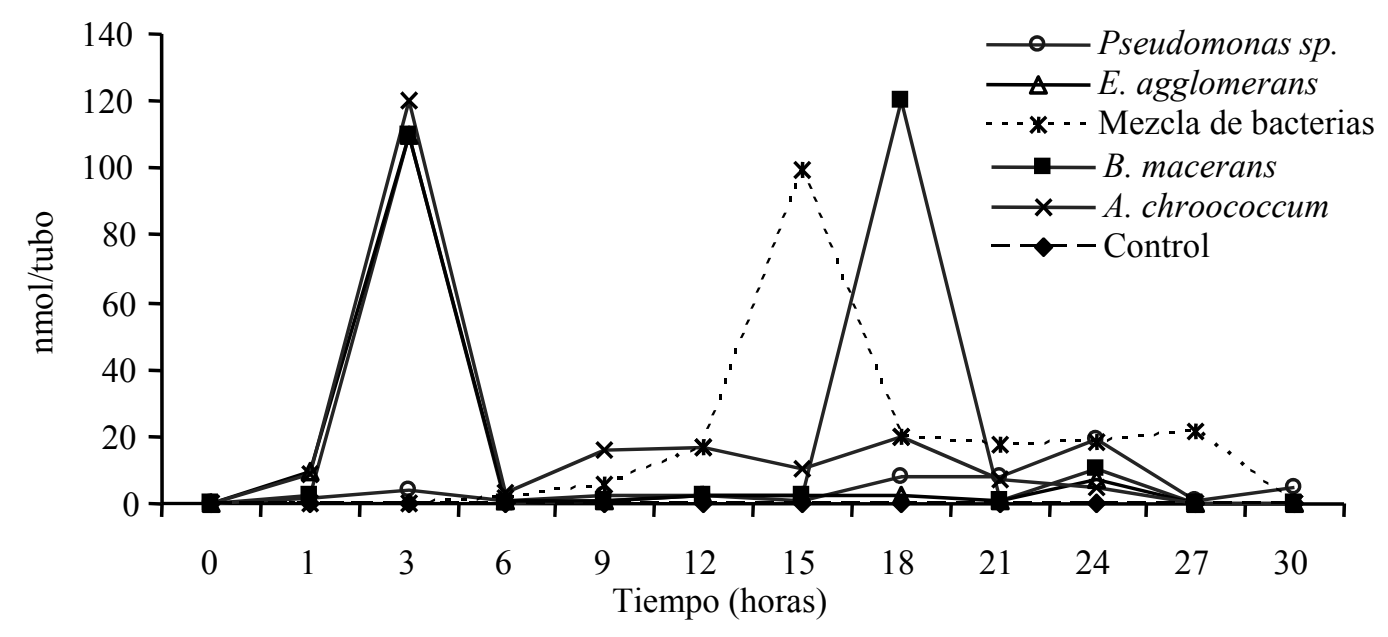

Figura 1. Ensayo de reducción de acetileno a las bacterias utilizadas en el ensayo in vivo. Acetylene reduction assay to bacteria used in the in vivo test.

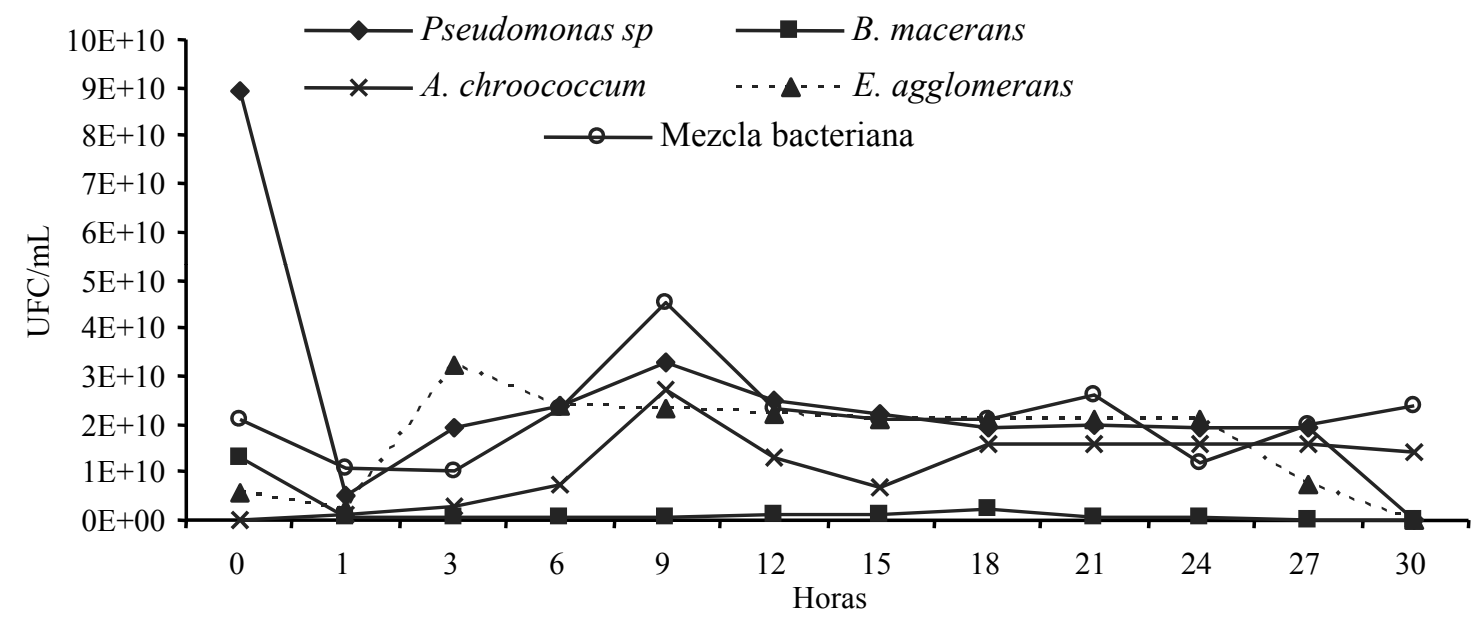

Figura 2. Crecimiento microbiano presentado durante la incubación en atmósfera de acetileno. Microbial growth during incubation in acetylene atmosphere. 


\section{DISCUSIÓN}

Cultivo, aislamiento e identificación. Algunas de las bacterias aisladas en este estudio también se han aislado en Colombia en árboles nativos. Especies bacterianas de los géneros Enterobacter, Pseudomonas, Pantoea, Burkholderia, Klebsiella y Arthrobacter se han aislado en Colombia de las especies nativas forestales pino romeron, cedro rosado, encenillo y pagoda (Deaza y Mesa 1996, Jiménez 1996, Parra 1996, Martínez-Nieto y García-González 2002). Aunque menos abundantes, las especies diazotróficas pertenecientes al género Pseudomonas han sido aisladas en el interior de tejidos radiculares de coníferas, en la rizósfera del pino Paraná (Araucaria angustifolia Kuntze), especie forestal en vías de extinción en Brasil, o en pilas de compost a partir de lodos provenientes de fábricas de papel (Chanway 1999, Beauchamp et al. 2006, Neroni y Cardoso 2007).

Ensayo in vivo de fijadores de nitrógeno. Los incrementos en la captación de nitrógeno y baja pérdida de este elemento en el suelo por las plántulas inoculadas con bacterias en comparación con las no inoculadas es un hallazgo importante si se tiene en cuenta que uno de los indicadores para determinar la calidad del suelo es el flujo de nitrógeno a través de la biomasa microbiana, determinando que la mayor eficiencia de un suelo o práctica agrícola está dada por el mayor porcentaje de nitrógeno mineralizado que es absorbido por la planta (Yakovchenko et al. 1996). Por otro lado, no todos los estudios reportan efectos positivos en el crecimiento vegetal al inocular bacterias fijadoras de nitrógeno o promotoras de crecimiento vegetal (Bashan y Bashan 2005, Saeed et al. 2007) como los obtenidos en esta investigación.

El efecto benéfico de la inoculación de fijadores de nitrógeno encontrado en $P$. patula ha sido reportado por varios investigadores en otras coníferas. Estudios realizados utilizando Azospirillum lipoferum en plántulas de roble (Quercus ithaburensis Dcne.) hallaron un incremento en la nutrición mineral y aumento en la biomasa (Zaady et al. 1993). La inoculación de semillas del abeto Douglas (Pseudotsuga menziesii (Mirb.) Franco) con Bacillus polymyxa aumentó significativamente el peso seco de raíces y brotes de las plántulas de esta conífera (Bashan et al. 1996). La inoculación de la especie amazónica utilizada en la producción de muebles, pino chuncho (Schizolobium amazonicum Huber ex Ducke), con microorganismos fijadores de nitrógeno y endomicorrizas incrementó la biomasa y la producción de madera (Siviero et al. 2008). En Colombia la utilización de A. lipoferum estimuló la germinación del cedro rosado y en plántulas de la misma especie la inoculación de esta bacteria junto con A. chroococcum produjo incrementos en la mayoría de los parámetros vegetales evaluados (Parra 1996). También se encontraron efectos benéficos con la inoculación de bacterias diazotróficas y solubilizadoras de fósforo en las especies altoandinas W. tomentosa y E. myrtilloides con relación a la altura de las plántulas (Martínez-Nieto y García-González 2002).

Por otro lado, se ha encontrado que las asociaciones tripartitas (hongo ectomicorrízico-bacterias asociadas-especie forestal) han resultado beneficiosas en suelos contaminados con metales pesados, ya que estudios recientes han demostrado que la colonización de plántulas del pino albar (Pinus sylvestris L.) con hongos ectomicorrízicos específicos y bacterias asociadas a éstos provee protección a la especie forestal contra el efecto de ciertos metales pesados como zinc, cadmio y plomo, siendo promisorio su uso para el establecimiento de plantaciones de coníferas en suelos contaminados con estos metales (Kozdrój et al. 2007).

Porcentaje de micorrización. El haber observado solamente en el tratamiento donde se inoculó conjuntamente $B$. macerans y $S$. luteus tanto colonización del hongo como presencia de bacterias aglutinadas en la raíz, concuerda con un estudio realizado con diferentes hongos ectomicorrízicos del género forestal Picea (Dietr.), entre los que se encuentra S. luteus, en donde encontraron principalmente bacterias Gram-positivas asociadas a la micorrizósfera (Karlifiski et al. 2007). Entre los beneficios de esta relación se encuentran el desarrollo de la ectomicorriza y acción antagónica contra hongos patógenos (Hampp y Maier 2004)

Se han reportado varios estudios de bacterias nitrofijadoras libres asociadas a ectomicorrizas en coníferas como pino, abeto y árboles nativos del sudeste asiático pertenecientes a los géneros Azospirillum, Bacillus, Beijerinkia y Clostridium principalmente (Duponnois y Garbaye 1991, Kikuchi y Ogawa 1995, Bashan et al. 1996). También se ha encontrado actividad de la enzima nitrogenasa en el sistema nodular de la asociación Suillus tomentosus /Pinus contorta var. Latifolia (Paul et al. 2007).

Los resultados obtenidos en este estudio no concuerdan con los encontrados por otros investigadores que reportan a Burkholderia sp., Paenibacillus sp., Rhodococcus sp., Pseudomonas fluorescens y Bacillus sp. como ayudadores de micorrización de ciertas especies fúngicas como, por ejemplo, Laccaria laccata en abeto Douglas y Lactarius rufus en pino albar (Garbaye 1994, Poole et al. 2001, Heinonsalo et al. 2004). Sin embargo, es importante resaltar que la colonización bacterial de las ectomicorrizas muestra cierta especificidad entre el hospedero y el simbionte, pudiendo influenciar positiva o negativamente en la micorrización y por ende en el crecimiento de las plantas (Garbaye 1994, Poole et al. 2001). Esta especificidad posiblemente está dada por el efecto combinado del tipo de suelo, el simbionte fúngico, la planta hospedero y la localización de las comunidades asociadas con las ectomicorrizas del árbol (Timonen et al. 1999, Kozdrój et al. 2007), haciendo entendible por qué no todas las bacterias inoculadas en $P$. patula colonizaron la raíz micorrizada o los diferentes niveles de micorrización encontrados. Por otro lado, Shishido et al. (1996) encontraron que diferentes especies de Bacillus incrementan el crecimiento longitudinal de las coníferas por mecanismos diferentes a la micorrización. 
Ensayo de la nitrogenasa. Hurek et al. (1994), trabajando con concentraciones deficientes de oxígeno disuelto con la bacteria fijadora de nitrógeno Azoarcus sp., observaron que se incrementó la tasa específica de respiración y la utilización de la fuente de carbono para la fijación de nitrógeno medida por el ARA, mientras la tasa de crecimiento no mostró cambios significativos. Estos resultados son similares con relación al crecimiento a los reportados en este estudio con las cuatro bacterias diazotróficas evaluadas.

Por otro lado, los hallazgos encontrados en esta investigación concuerdan con lo reportado por David y Fay (1977), los cuales realizaron diferentes ensayos con la prueba de reducción de acetileno, para probar el efecto prolongado de incubación con este gas sobre los microorganismos diazotróficos. Estos autores encontraron en Azotobacter vinelandii un declive en el pico de actividad después de tres horas, el cual se recobró parcialmente después de las nueve horas. Esto se debe, posiblemente, a que el acetileno previene la síntesis de amonio cuando permanece por mucho tiempo en el medio a concentraciones suficientes para saturar la nitrogenasa, provocando depleción de nitrógeno en las células. Ello induce a activación y nueva síntesis de la enzima para la fijación de nitrógeno (David y Fay 1977, Staal et al. 2001, Kästner y Blöchl 2005). Con base en estos hallazgos y los encontrados en esta investigación no se hace necesario prolongar la incubación con acetileno, principalmente cuando el objetivo es determinar la presencia de la enzima nitrogenasa. Además es una reacción inútil fisiológicamente para los diazotróficos, con gasto de ATP.

La variación de actividad en los microorganismos diazotróficos, además de la inherente a la cepa aislada, también se debe a las condiciones del ensayo de reducción de acetileno, el cual depende de varias condiciones fisicoquímicas, principalmente $\mathrm{pH}$, presión de oxígeno, fuente de carbono y concentración de nitrógeno combinado (Pham y Burgess 1993, Zhang et al. 1993, Klassen et al. 1997, Limmer y Drake 1998, Beauchamp et al. 2006). Dada la gran variabilidad presente en el ensayo de reducción de acetileno, Montoya et al. (1996) recomiendan una calibración directa del procedimiento de reducción de acetileno con el protocolo de $\mathrm{N}^{15}$ para que pueda ser utilizada en la cuantificación de la medida de fijación de nitrógeno y Staal et al. (2001) validan el ARA mediante una modificación del ensayo con flujo constante de etileno. Sin embargo, a pesar de estas desventajas esta técnica se sigue utilizando actualmente en diversas investigaciones dada su sensibilidad, bajo costo y rapidez (Beauchamp et al. 2006, Paul et al. 2007).

\section{CONCLUSIONES}

Se observan incrementos en la captación de nitrógeno y estimulación del crecimiento vegetal con la inoculación de la mayoría de bacterias aisladas, indicando el potencial de estos microorganismos como promotores de crecimiento vegetal y posibles biofertilizantes.

\section{AGRADECIMIENTOS}

Los autores agradecen al Instituto Colombiano para el Desarrollo de la Ciencia y la Tecnología "Francisco José de Caldas", COLCIENCIAS, INDERENA e Instituto Alexander von Humboldt por la financiación de la investigación; como también a la Corporación Colombiana de Investigación Agropecuaria -CORPOICA-TIBAITATA, laboratorio de Recursos Biofísicos, por prestar sus instalaciones, investigadores y técnicos para la realización de la prueba de reducción de acetileno.

\section{REFERENCIAS}

Alvarado B. 1989. Métodos de propagación e inoculación de Amanita muscaria en Pinus patula y Cupressus lusitanica. In Sieverding E, M Sánchez de Prager y N Bravo ed. Investigación sobre micorrizas en Colombia. Segunda Edición. Palmira, Colombia. Fondo FEN Colombia. p. 188-193.

Bashan Y, H Levanony, R Ferrera-Cerrato. 1996. Interacciones entre plantas y microorganismos benéficos: II bacterias asociativas de la rizósfera. Terra 14(1): 159-183.

Bashan Y, LE de Bashan. 2005. Plant growth promoting. Consultado 20 ene. 2008. Disponible en http://www.bashanfoundation. org/gmaweb/pdfs/bacterias.pdf

Beauchamp C, G Lévesque, D Prévost, F Chalifour. 2006. Isolation of free-living dinitrogen-fixing bacteria and their activity in compost containing de-inking paper sludge. Bioresource Technology 97(8): 1002-1011.

Chanway CP. 1997. Inoculation of tree roots with plant growth promoting soil bacteria: an emerging technology for reforestation. Forest Science (USA) 43(1): 99-112.

Chanway CP. 1999. Nitrogen fixing pine? Faculty of ForestryNewsletter- The University of British Columbia. Consultado 4 may. 2006. Disponible en www.forestry.ubc.ca/brchline/99dec/ fs.htm

David K, P Fay. 1977. Effects of long-term treatment with acetylene on nitrogen-fixing microorganisms. Applied and Environmental of Microbiology 34(6): 640-646.

DAMA (Departamento Administrativo del Medio Ambiente, CO), Corporación Suna Hisca. 2003. Plantaciones exóticas Parque ecológico distrital de montaña Entrenubes. Tomo I. Componente biofísico. Bogotá, Colombia. Consultado 14 jun. 2006. Disponible en http://www.secretariadeambiente.gov.co/ sda/libreria/pdf/ecosistemas/areas_protegidas/en_a1.pdf

Deaza J, C Mesa. 1996. Aislamiento y caracterización de bacterias fijadoras de nitrógeno microaerofílicas asociadas a rizósfera de Nageia rospigliosii (Pilger Laubenfels). Tesis de grado Bacteriología. Bogota, Colombia. Facultad de Ciencias Básicas, Pontificia Universidad Javeriana. 89 p.

Duponnois R, J Garbaye. 1991. Effect of dual inoculation of Douglas fir with ectomycorrhizal fungus Laccaria laccata and mycorrhization helper bacteria (MHB) in two bare root forest nurseries. Plant and Soil 138: 169-176. 
Fisher RF, D Binkley. 2000. Biology of forest soils. Chapter 6. Consultado 5 abr. 2006. Disponible en www.for.nav.edu/ courses/hart/for521/fisher\%20and\%20Binkley\%202000/ Chapter06.doc

Fujii I, Y De Huang, A Higoshitani, Y Nishimura, S Iyama, Y Hirota, T Yoneyama, R Dixon. 1987. Effect of inoculation with Klebsiella oxytoca and Enterobacter cloacae on dinitrogen fixation by rice-bacteria association. Plant and Soil 103: 221-226.

Garbaye J. 1994. Helper bacteria: a new dimension to the mycorrhizal symbiosis. New Phytologist 128: 197-220.

Hampp R, A Maier. 2004. Interaction between soil bacteria and ectomycorrhiza-forming fungi. Plant Surface Microbiology. Consultado 14 mar. 2008. Disponible en http://www.cababstractsplus.org/google/abstract.asp? AcNo=20043174749

Heinonsalo J, P Frey-Klett, JC Pierrot, L Churin, D Vairelles, J Garbaye. 2004. Fate, tree growth effect and potential impact on soil microbial communities of mycorrhizal and bacterial inoculation in a forest plantation. Consultado 25 mar. 2008. Disponible en http://www.sciencedirect.com/ science?_ob=ArticleURL\&_udi=B6TC7-49S6RRJ-5\&_ user $=10 \& \_$rdoc $=1 \& \_\mathrm{fmt}=$ \&_orig=search\&_sort $=\mathrm{d} \&$ view $=\mathrm{c} \& \_$ acct $=\mathrm{C} 000050221 \&$ _version $=1 \&$ \&urlVersion $=0 \&$ _userid $=1$ $0 \& \mathrm{md} 5=7 \mathrm{fa} 403 \mathrm{~d} 3424 \mathrm{efed} 6 \mathrm{bd} 82 \mathrm{e} 7 \mathrm{aa} 075 \mathrm{c} 5 \mathrm{ce} 0$

Holt J, M Krieg, P Sneath, J Staley, S Williams. 1994. Bergey's manual of determinative bacteriology. 9th Edition. Baltimore, USA. Williams \& Wilkins. 789 p.

Hurek T, B Reinhold, G Turner, F Bergersen. 1994. Augmented rates of respiration and efficient Nitrogen Fixation at nanomolar concentrations of dissolved $\mathrm{O}_{2}$ in Hyperinduced Azoarcus sp. Strain BH72. Journal of Bacteriology 176 (15): 4726-4733.

Jiménez A. 1996. Aislamiento y caracterización de diazotróficos microaerofílicos presentes en suelos rizosférico y raíces de Cedrela montana. Tesis de grado Bacteriología. Bogotá, Colombia. Facultad de Ciencias Básicas, Pontificia Universidad Javeriana. $113 \mathrm{p}$.

Karlifiski L, S Ravnskov, B Kieliszewska-Rokicka, J Larsen. 2007. Fatty acid composition of various ectomycorrhizal fungi and ectomycorrhizas of Norway spruce. Soil Biology and Biochemistry 39 (4): 854-866.

Kästner J, PE Blöchl. 2005. Model for acetylene reduction by nitrogenase derived from density functional theory. Inorganic Chemistry 44 (13): 4568-4575.

Kikuchi J, M Ogawa. 1995. Nitrogen-Fixing (Acetylene Reducing) Activity in the Mycorrhizas of Dipterocarp Seedling. Consultado 31 ene. 2006. Disponible en http://www.metla.fi/iufro/ iufro95abs/d7pap6.htm

Klassen G, F Pedrosa, E Souza, S Funayama, L Rigo. 1997. Effect of nitrogen compounds on nitrogenase activity in Herbaspirillum seropedicae SMR1. Canadian Journal of Microbiology 43: 887-891.

Kozdrój J, Z Piotrowska-Seget, P Krupa. 2007. Mycorrhizal fungi and ectomycorrhiza associated bacteria isolated from an industrial desert soil protect pine seedlings against $\mathrm{Cd}(\mathrm{II})$ impact. Ecotoxicology 16 (6): 449-456. Consultado 14 mar. 2008. Disponible en http://www.ingentaconnect.com/content/ klu/ectx/2007/00000016/00000006/00000149; jsessionid =20 831f4tigjf6.victoria

León M, J Ortiz, FA López. 1993. Diagnóstico de daños nutricionales en cuatro especies forestales empleadas en reforestaciones.
Instituto Nacional de los Recursos Naturales y del Ambiente, INDERENA-. Antioquia, Colombia. La Imprenta Nacional de Colombia. 88 p.

Limmer C, HL Drake. 1998. Effects of carbon, nitrogen, and electron acceptor availability on anaerobic $\mathrm{N}_{2}$-fixation in a beech forest soil. Soil Biology and Biochemistry 30 (2): 153-158.

Martínez- Nieto P, G García-González. 2002. Aislamiento y evaluación preliminar de bacterias rizosféricas diazotróficas y solubilizadoras de fósforo de las especies forestales altoandinas Weinmannia tomentosa y Escallonia myrtilloides. Resúmenes Congreso Mundial de Páramos. Boyacá, Colombia. Impreso por Panamericana Formas e Impresos S.A. p 68.

Montoya J, M Voss, P Kahler, D Capone. 1996. A simple, highprecision, high-sensivity Tracer Assay for $\mathrm{N}_{2}$ Fixation. Applied and Environmental Microbiology 62 (3): 986-993.

Neroni R, E Cardoso. 2007. Occurrence of diazotrophic bacteria in Araucaria angustifolia. Scientia Agricola 64 (3): 303-304.

Novo R. 1993. Microbiología y química de suelos. Memorias Curso. Bogotá, Colombia. Programa de Educación continuada, Pontificia Universidad Javeriana. 20 p.

Orozco C. 1989. Selección y cultivos de hongos micorrízicos para Pinus caribae. In Sieverding E, M Sánchez de Prager y N Bravo ed. Investigación sobre micorrizas en Colombia. Palmira, Colombia. Segunda Edición. Palmira, Colombia. Fondo FEN Colombia. p. 125-137.

Parra C. 1996. Efecto de la inoculación de bacterias fijadoras de nitrógeno en el desarrollo inicial de Cedrela montana Turczaninov (Cedro rosado). Tesis de grado Bacteriología. Bogotá, Colombia. Facultad de Ciencias Básicas, Pontificia Universidad Javeriana.124 p.

Paul LR, BK Chapman, CP Chanway. 2007. Nitrogen fixation associated with Suillus tomentosus tuberculate ectomycorrhizae on Pinus contorta var. latifolia. Annals of Botany 99 (6): 1101-1109.

Pham D, B Burgess. 1993. Nitrogenase Reactivity: Effect of $\mathrm{pH}$ on substrate reduction and $\mathrm{CO}$ inhibition. Biochemistry 32 (49): 13725-13761.

Poole EJ, GD Bending, JM Whipps. 2001. Bacteria associated with Pinus sylvestris-Lactarius rufus ectomycorrhizas and their effects on mycorrhiza formation in vitro. New Phytologist 151 (3): 743-751.

Presidencia de la República de Colombia. 2005. Cultivos forestales podrían generar 760 mil empleos. Consultado 14 jun. 2006. Disponible en http://www.presidencia.gov.co/sne/2005/ enero/27/052722005.htm

Rösch C, A Mergel, H Bothe. 2002. Biodiversity of denitrifying and dinitrogen-fixing bacteria in an acid forest soil. Applied and Environmental Microbiology 68 (8): 3818-3829.

Saeed B, M Sajjad, A Bano, K Malik. 2007. Coinoculation of chickpea with Rhizobium isolates from roots and nodules and phytohormone-producing Enterobacter strains. Australian Journal of Experimental Agriculture 47 (8): 1008-1015.

Shishido M, HB Massicotte, CP Chanway. 1996. Effect of plant growth promoting Bacillus strains on pine and spruce seedling growth and mycorrhizal infection. Annals of Botany 77: 433-441.

Staal M, S Lintel-Hekkert, F Harren, L Stal. 2001. Nitrogenase activity in cyanobacteria measured by the acetylene reduction 
assay: a comparison between batch incubation and on-line monitoring. Environmental Microbiology 3 (5): 343-351.

Siviero M, A Marega, D Dos Santos, R Roselli, S Yun, I Abonizio, L Sayuri, C Castro, M Horta, W Zangaro, M Nogueira, G Andrade. 2008. Interaction among N-fixing bacteria and AM fungi in Amazonian legume tree (Schizolobium amazonicum) in field conditions. Applied Soil Ecology 39 (2): 144-152.

Timonen S, K Jorgensen, K Haahtela, R Sen. 1999. Bacterial communities at defined locations of Scots pine mycorrhizospheres in dry pine forest humus and nursery peat. Consultado 31 ene. 2006. Disponible en http://www.icom2.slu.se/ABSTRACTS/ Timonen.html

Varón LF. 1999. Reforestación, inversión con buena cosecha. Revista el Mueble y la Madera 24: 9-14.
Villegas JC. 2004. Análisis del conocimiento en la relación aguasuelo-vegetación para el departamento de Antioquia. Revista Escuela de Ingeniería de Antioquia EIA 1: 73-79.

Yakovchenko V, L Sikora, D Kaufman. 1996. A biologically based indicator of soil quality. Biology and Fertility of Soils 21:245-251.

Zaady E, A Prerevolotsky, Y Okon. 1993. Promotion of plant growth by inoculums with aggregated and single cell suspensions of Azospirillum brasilense. Soil Biology and Biochemistry 25 (7): 819-823.

Zhang Y, R Burris, P Ludden, G Roberts. 1993. Posttranslational regulation of nitrogenase activity by anaerobic and ammonium in Azospirillum brasilense. Journal of Bacteriology 175 (21): 6781-6788. 